\title{
THE SYNDROME OF SEX-LINKED HYDROCEPHALUS
}

\author{
BY \\ J. H. EDWARDS* \\ From the Medical Research Council, Population Genetics Research Unit, Oxford
}

(RECEIVED FOR PUBLICATION MARCH 21, 1961)

Bickers and Adams (1949) and Edwards, Norman and Roberts (1961) have presented detailed neuropathological examinations on two cases of hydrocephalus secondary to aqueductal stenosis in families with many hydrocephalic males. These, taken together, provide incontrovertible evidence of a specific syndrome with sex-linked recessive inheritance. In this paper further families are described in which the same disorder appears to be manifest, although the basic observation of the neuropathology has not been made.

\section{HISTORICAL}

Borle (1953) has reviewed the reports of familial hydrocephalus; Gellman (1959) has reviewed reports of hydrocephalic twins, and Bickers and Adams have reviewed reports of aqueductal stenosis. Both Borle, and Bickers and Adams give detailed summaries. Although various familial cases, and some cases in which aqueductal stenosis was present, might plausibly be interpreted as exemplifying this variety of sex-linked hydrocephalus, no report previous to that of Bickers and Adams gives both familial and pathological data in adequate detail to define an entity.

Recent reports which are strongly suggestive of sex-linked hydrocephalus include Perez and Linger's (1947) report on a sibship with three affected stillborn boys, one with a bifid scrotum, and two normal girls. Bamatter (1949) quoted the case of a woman with two hydrocephalic boys and three normal girls. Zimmer (1952) reported two sisters of whom one had two stillborn hydrocephalic males and the other one stillborn hydrocephalic male, and gave brief histological details, referring to the increased vasculature and gliosis on the dorsal side of the mid-brain and hind-brain. No mention was made of the aqueduct. Borle (1953) reported three hydrocephalic brothers, two of whom were identical twins, the only children of healthy parents. The eldest, age 8, showed no abnormalities apart

* Present address: The Children's Hospital of Philadelphia. from a slight enlargement of the head $(3.8 \mathrm{~cm}$. above average) and lack of concentration. His twin brothers, age 5, were normal at birth, hydrocephalus developing insidiously and being apparent only after the first year. Walking started at the age of 2, speech at the age of 4 . Both developed epilepsy at 8 months, an unusual complication of hydrocephalus. The family exemplifies some of the difficulties of applying any of the theoretical models of ascertainment, the diagnosis of hydrocephalus in the first case being made only after consideration of similarities to the other two. Gellman (1959) referred to identical twin boys, age 5, with hydrocephalus and mental deficiency. Air studies showed moderate symmetrical ventricular dilatation. The photographs are strikingly similar to those of the two brothers (Figs. 1 to 6) showing a large oblong head, thin legs, and apparent inability to plantigrade with the knees straight; one shows opposition of the thumbs.

\section{CASE REPORTS}

Family I: The Bromyard Family

The presenting cases, Glynn (Figs. 1, 2, 3; IV 15 in Fig. 7) and Martin (Figs. 4, 5, 6; IV 16 in Fig. 7) were referred simultaneously to Dr. Clifford Parsons by Dr. M. J. Peto with the comment that the family suffered from hereditary hydrocephalus affecting only the males.

Glynn, age 9. (The Children's Hospital, Birmingham. EB/137960.) Caesarian delivery after radiological diagnosis of hydrocephalus during prolonged labour. Birth weight $7 \mathrm{lb}$. $6 \mathrm{oz}$. At birth both thumbs were turned in across the palms. Development was slow up to the age of 3, after which there has been little advance, and he has persisted with the mental attributes of a 2-year-old. $\mathrm{He}$ is a happy and active child. Intelligence testing suggested rather more advanced development with a mental age of 2.9 years (I.Q. 30), but he was not fully continent and knew few words.

Physical examination. No abnormality was apparent apart from the head, hands and stance. The head was irregularly enlarged, approximately $2.5 \mathrm{~cm}$. above the average circumference for that age, and unusually oblong. 


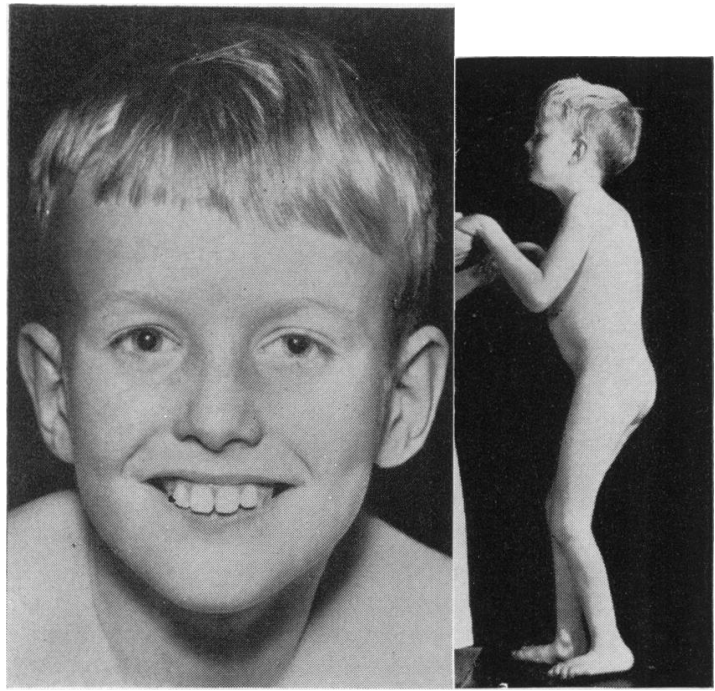

FIG. 1.-Glynn: face.

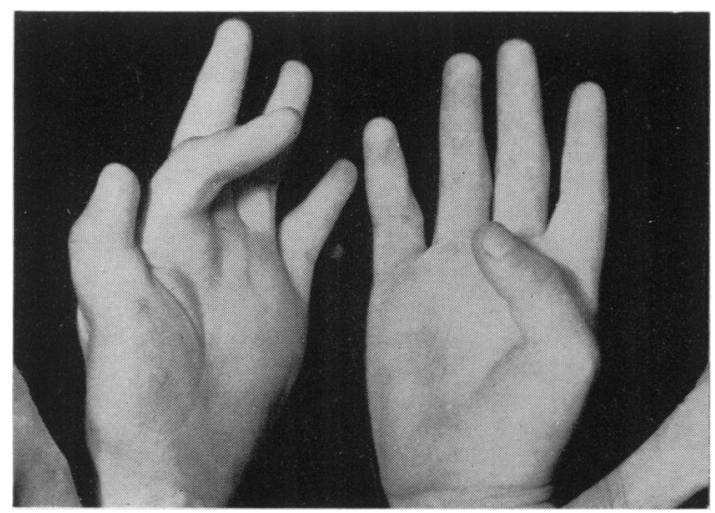

FiG. 3.-Glynn: hands.

The face appeared somewhat coarse. The eyes were rather deep set. White flakes were present on the irides: these did not show the typical horseshoe-shaped fibrous strands seen in mongolism and the irides were otherwise well developed. The hands and stance were as shown. The reflexes were not increased in the arms, which showed full power and no increased tone. The legs showed marked spasticity with loss of power and very brisk reflexes. The plantar responses were extensor.

Investigations showed urine with amino acid and sugar chromatography normal, and concentration and dilution test normal; blood with electrolytes and proteins normal; urea $31 \mathrm{mg} . / 100 \mathrm{ml}$.

Radiograph showed large cranial vault, but no evidence of cause of hydrocephalus.

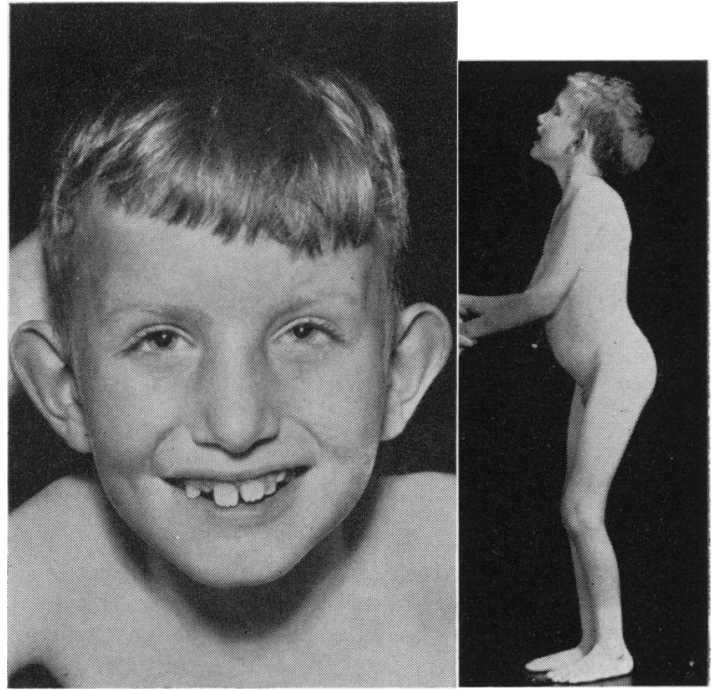

FIG. 4.-Martin: face.

FIG. 5.-Martin: stance.

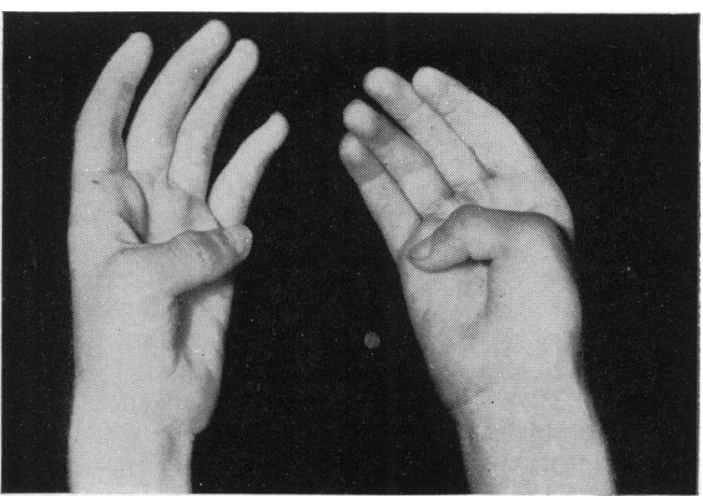

FIG. 6.-Martin: hands.

An electroencephalogram revealed diffuse symmetrical abnormalities; no epileptic phenomena were present.

Martin, age 8. (The Children's Hospital, Birmingham. EB/137961.) Full-term normal delivery; birth weight $6 \mathrm{lb}$. $5 \mathrm{oz}$. The head did not appear large at birth and the parents had not noticed any subsequent enlargements. The hands were like Glynn's with in-turning of the thumb apparently uninfluenced by operative procedures. He sat up at 6 months, walked at 12 months, but has never talked properly. Speech appeared slurred but there were no other cerebellar signs. Progress seemed to slow markedly at the age of about 1 year; at the age of 8 he had a mental age of about 2 years and was somewhat more retarded than his brother. 


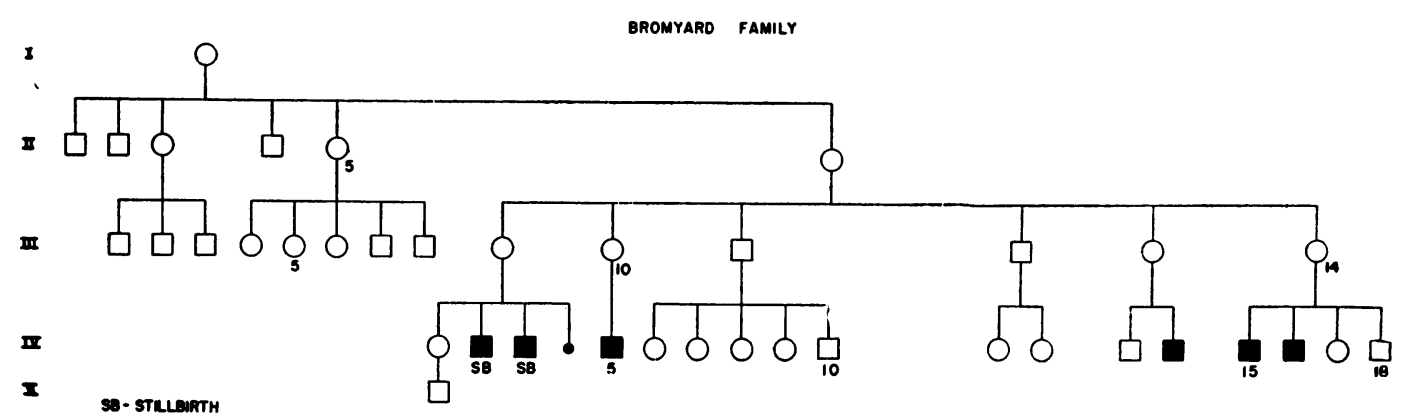

Fig. 7.-Family I: The Bromyard family.

Physical findings. These were identical to those described above. Apart from a slight difference in size these boys could easily be mistaken for identical twins.

Investigations on the urine revealed amino acid and sugar chromatography normal, and concentration and dilution test normal; blood, electrolytes and proteins were normal; urea $49 \mathrm{mg} . / 100 \mathrm{ml}$.

A radiograph showed a large cranial vault with a long type of skull, slightly asymmetrical with probably premature closure of the sagittal sinus.

The hands showed short thumbs and first metacarpals.

An electroencephalogram indicated diffuse symmetrical abnormality, but no epileptic phenomena.

Family History. Through the kindness of Dr. Clifford Parsons and Dr. M. J. Peto, the family was visited. All living affected members, the mothers of all cases, and their grandmother were interviewed and given a detailed neurological examination including ophthalmoscopy. The pedigree (Fig. 7) shows six cases among the male children of four sisters. The grandmother (II 6) whose ancestry is from South Wales, must be assumed heterozygous for the defective gene: there is no evidence of any prior affected member and she has three normal brothers (II 1, 2, 4) and two sisters (II 3, 5) with three and two normal sons respectively.

IV. 1. Normal girl with normal son (V 1) age 6 months.

IV. 2. Induced delivery with perforation after intrauterine death. Hydrocephalus obvious (personal report from practitioner). Weight $12 \mathrm{lb}$.

IV. 3. Delivered dead after induction; hydrocephalic; weight $12 \mathrm{lb}$.

IV. 4. Spontaneous abortion at third month.

IV. 5. Colin, age 18. Normal delivery, $7 \frac{1}{2} \mathrm{lb}$. Normal infancy until head started enlarging at about 2 years of age. Head now long, irregular with slight bi-temporal bulges and a rather flat top; circumference $57 \mathrm{~cm}$. Squint with the left eye turning in, which was said to have developed before enlargement of the head. Mental age about 3 years.

ExAMINATION. Cranial nerves and eyes were normal, apart from squint. Generalized weakness and poor co-ordination of arms, with normal or slightly increased tone and reflexes. Thumb is held across palm; structure confused by various orthopaedic procedures designed to correct this. Severe spasticity of legs with wasting, but basic disturbance confused by numerous operations; moderately brisk knee and ankle jerks; plantar responses definitely flexor.

IV. 14. Michael, age 12. Normal at birth. Sat at the age of 1 year and then made very little progress until starting speech at the age of 2 years. Intelligence at about 4-year-old level. Can speak well and ride a tricycle.

EXAMINATION. A healthy child with a slightly large head (53 cm.). Thumbs rather short and conical and tend to be held across palm. Arm reflexes normal. Unable to plantigrade due to contracture of calf muscles; tone greatly increased, but power good; knee jerks very brisk; ankle jerks normal; plantar responses extensor.

IV. 15. Glynn-see above.

IV. 16. Martin-see above.

IV. 17. Normal girl.

IV. 18. Normal boy, age 1. Hands, fontanelles and mental development normal for age.

\section{Family II: The Thetford Family}

Maurice. This case, which is probably sporadic (Maurice, IV 5; Fig. 8) is number 86 in Penrose's series of malformations of the nervous system where it is described as a case of hydrocephalus with flexion deformity of the thumbs (Penrose, 1946). (I am grateful to Professor Penrose for giving me a copy of his original notes and permitting me to visit the patient.) When seen in 1958 he was a large robust mentally deficient man, living at home as the only child of elderly parents with a local ancestry.

At birth, when his mother was 38 , he appeared normal (weight $6 \mathrm{lb} .2 \mathrm{oz}$.), except that the thumbs were held in flexion across the palms. For the first year mental development was normal and speech started at 12 months, although physical development was slow and he still could not sit up unaided. After 12 months there was very slow progress, sitting unsupported at 3 years and walking at 5 . His head was noticed to be large at 1 year, and continued enlarging until he was 5 . Since then he 
has made little progress and now has a mental age of about 3 years. He is continent, can dress, goes out alone, and is said to be able to identify all the local cars and buses by sound.

Examination. He had a fairly large irregular head, the enlargement being largely antero-posterior with a high occiput; circumference $60 \mathrm{~cm}$. The face was asymmetrical, the left eye being sunken and below the right. The mouth and teeth appeared normal, apart from an unusually small right upper lateral incisor. The hands were normal, but he had rather small, probably atrophic, thumbs which were held almost permanently within the palm, but which could be extended and abducted either actively or passively without difficulty. His gait was grossly disturbed due mainly to inability to plantigrade. Ophthalmoscopy normal; colour vision normal. Cranial nerves normal. Tone, power and reflexes normal in arms. He is left-handed, has no cerebellar signs. (Although cerebellar signs were looked for in all patients and found in none, only in this patient was there sufficient co-operation to allow a reliable opinion on the absence of minimal signs.) Legs were distorted by contracture and wasting of the calf muscles, power probably slightly reduced; tone increased; knee jerks symmetrically increased; ankle jerks normal but in view of the small volume of calf muscle this probably represented abnormal excitability. Plantar responses extensor.

Family History. This was essentially negative. The mother of the case, III 5, was an intelligent woman, well informed about her family. Her eldest sib, III 1, died shortly after birth; she knows of no details except that there was no obvious cause and is uncertain of the sex. Another sib, a boy, III 2, died between the ages of 1 and 2 and is said to have been a normal child without abnormality of development, head size or hands. As these deaths were discussed in the family in relation to Maurice, this negative evidence appears reliable. Her mother's four sisters and two brothers were all healthy and all had two, three or four normal children.

In spite of the absence of both familial and pathological evidence the consistency of the complex of signs leads me to regard this case as a very likely example of sex-linked hydrocephalus. The high maternal age is possibly not fortuitous.

\section{Family III: The Northampton Family}

This pedigree (Fig. 9) was brought to my notice by Dr. Christopher Ounsted as a family exhibiting mental deficiency segregating as a sex-linked recessive with an unusually large proportion of affected males. I am most grateful to him and to Dr. I. H. Gosset, to whom the family is also well known, for their help. As usual, there cannot be said to be a propositus and the cases will be described in order of seniority starting with the larger sibship.

IV. 3. Alfred, age 17. Normal birth. He was slow in sitting and talking and has a mental age of about $2 \frac{1}{2}$ years. He has had three fits; is abnormally active and restless with a very short attention span. His head is oblong and irregular, $74 \mathrm{~cm}$. in circumference; face asymmetrical with left eye raised. Arms show normal reflexes and normal power and tone. Right thumb is held opposed across palm. There is marked spasticity of legs with brisk jerks, loss of power, but no wasting. He cannot plantigrade, and plantar responses are definitely flexor. Radiograph of skull at the age of 3 suggested hydrocephalus.

THETFORD FAMILY

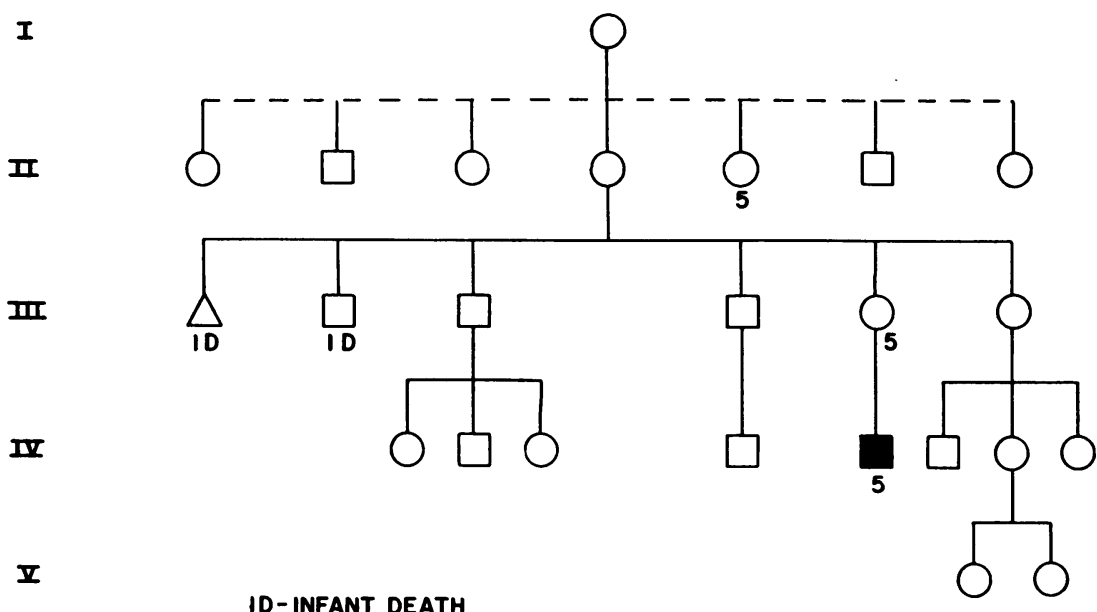

FIG. 8.-Family II: The Thetford family. 


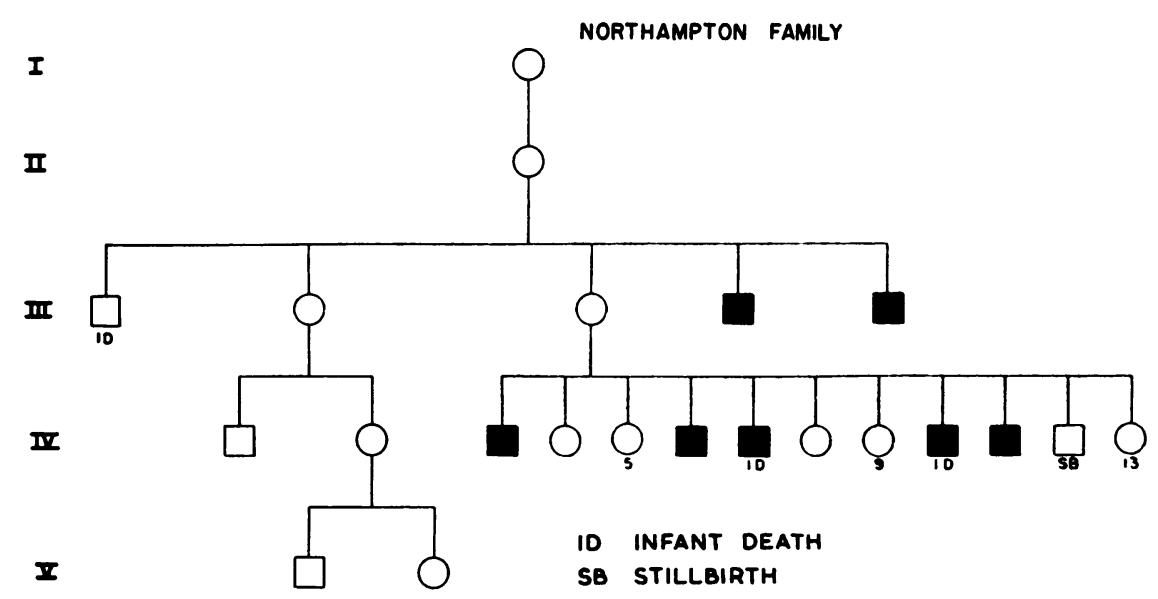

FIG. 9.-Family III: The Northampton family.

IV. 4. Normal girl.

IV. 5. Normal girl.

IV. 6. Aubrey, age 13. Appearance similar to IV. 3. Head is long and irregular. Face asymmetrical with right eye raised. Skull circumference is $53 \mathrm{~cm}$. Mental age is about 3 years. Hands are normal apart from slightly small terminal phalanges to thumb. No neuromuscular abnormality apart from slightly brisk leg reflexes and abnormal tenseness of soleus; no ankle clonus; plantar responses flexor; can plantigrade foot.

IV. 7. Allan. Died age 4 months. During life showed obvious asymmetry of skull and was always sickly and too weak to feed properly. No autopsy was carried out.

IV. 8. Normal girl.

IV. 9. Premature baby girl, who died shortly after delivery. No abnormality noted.

IV. 10. Boy, died age 9 weeks. Clinical diagnosis on admission to hospital hydrocephalus and dehydration. At autopsy no abnormalities were found. The slides of the mid-brain did not include the aqueduct. In spite of the absence of pathological evidence it seems unwise to ignore the clinical diagnosis, and, as with the previous case, the balance of evidence appears to favour hydrocephalus.

IV. 11. Andrew, age 5. Face asymmetrical, skull circumference $53 \mathrm{~cm}$. Mental age about $2 \frac{1}{2}$ years. No abnormalities on examination apart from rather small thumbs and a definitely abnormal increase of leg reflexes and tension of soleus. Plantar responses flexor. Recently had repair of squint.

IV. 12. Stillborn boy; no adequate history from mother; hospital notes lost.

IV. 13. Normal girl.

II. 1. Died five years ago; came from nearby town and was an only child.

III. 1. Died of meningitis between 2 and 3 years of age; details unknown.

III. 2. Not interviewed, but well known to III 3.
Reports on the normality of her son (IV 1) and her daughter's son (V 1) appear reliable.

III. 3. Normal woman age 41 with no abnormal neurological signs apart from low intelligence.

III. 4. George, age 38. Institutionalized mentally defective man. A healthy, cheerful imbecile who can just dress and feed himself. Head rather long and irregular. Face asymmetrical with left eye higher than right. 'Prize-fighter's facies.' Thumbs show tendency to turn in. Terminal phalanges very small. Calf muscles contracted and feet clawed. Fundi normal. Power, tone and reflexes normal in arms. Legs spastic with slight loss of power and very brisk jerks. Plantar responses equivocal. Abnormal patchy pigmentation of skin.

III. 5. Sydney, age 32. Facies and intellect similar to above. Head long and irregular, $59.5 \mathrm{~cm}$. in circumference. Hands probably normal; arms normal. Legs spastic with very brisk jerks, but with no contractures or wasting. Plantar responses unequivocally flexor.

The low intelligence of the parents of this large family, the death of the grandparents, the confusion generated among themselves by giving all their children similar names, and the mildness of manifestation, make this family the least adequately studied. The three eldest cases are, however, fairly typical, and the family was identified by observing one of these, Alfred, while passing their house.

\section{Family IV: The Southampton Family}

This family has been described in detail in the previous paper (Edwards et al., 1961). Peter (IV 1), the only survivor of infancy of the 15 affected cases, died at the age of 18 . He was a low grade mental defective with a very large head which he could only carry with difficulty. He could just walk and talk, was liable to violent tempers, and had the curious habit of holding his thumb within 
TABLE 1

SEX-LINKED HYDROCEPHALUS

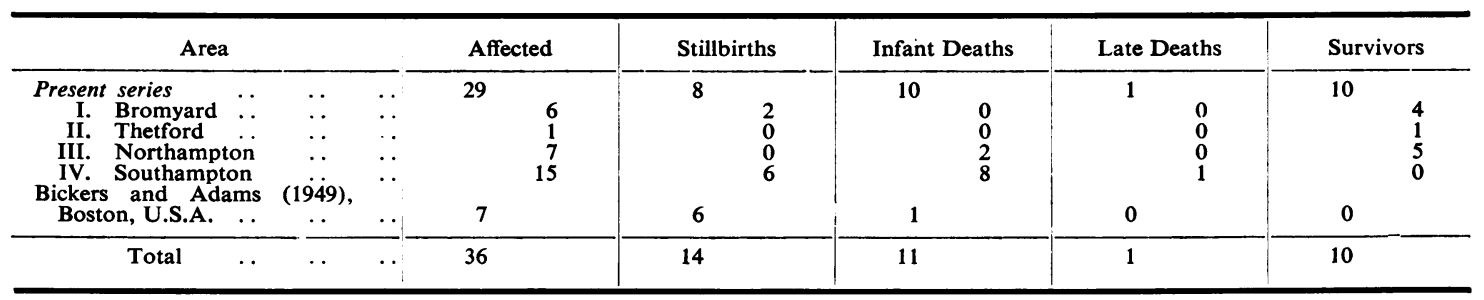

TABLE 2

A SUMMARY OF SIGNS IN 10 CASES PERSONALLY EXAMINED

\begin{tabular}{|c|c|c|c|c|c|c|c|c|c|c|c|c|c|}
\hline Family & Identific & cation & $\begin{array}{r}\text { Age } \\
\text { (yrs) }\end{array}$ & $\begin{array}{c}\text { Approx- } \\
\text { imate } \\
\text { Mental } \\
\text { Age } \\
\text { (yrs) }\end{array}$ & $\begin{array}{c}\text { Head } \\
\text { Circum- } \\
\text { ference } \\
\text { (cm.) }\end{array}$ & $\begin{array}{c}\text { Irregu- } \\
\text { lar } \\
\text { Head }\end{array}$ & $\begin{array}{c}\text { Asym- } \\
\text { metrical } \\
\text { Face }\end{array}$ & Squint & $\begin{array}{c}\text { Thumbs } \\
\text { In- } \\
\text { turned }\end{array}$ & $\begin{array}{l}\text { Spasti- } \\
\text { city of } \\
\text { Legs }\end{array}$ & $\begin{array}{c}\text { Con- } \\
\text { tracture } \\
\text { of Calf }\end{array}$ & $\begin{array}{c}\text { Babin- } \\
\text { ski } \\
\text { Res- } \\
\text { ponse }\end{array}$ & $\begin{array}{l}\text { Other } \\
\text { Signs }\end{array}$ \\
\hline Bromyard (I) & $\begin{array}{l}\text { Colin } \\
\text { Michael } \\
\text { Glynn } \\
\text { Martin }\end{array}$ & $\begin{array}{lr}\text { IV } & 5 \\
\text { IV } & 14 \\
\text { IV } & 15 \\
\text { IV } & 16\end{array}$ & $\begin{array}{r}19 \\
12 \\
9 \\
8\end{array}$ & $\begin{array}{l}3 \\
4 \\
2 \\
2\end{array}$ & $\begin{array}{l}57 \\
53 \\
53 \\
53\end{array}$ & $\begin{array}{l}+ \\
+ \\
+ \\
+\end{array}$ & $\begin{array}{l}+ \\
+ \\
+\end{array}$ & $\frac{+}{+}$ & $\begin{array}{l}+ \\
\pm \\
+ \\
+\end{array}$ & $\begin{array}{l}+ \\
+ \\
+ \\
+\end{array}$ & $\begin{array}{c}++ \\
+ \\
+ \\
+\end{array}$ & $\begin{array}{l}\bar{t} \\
+ \\
+\end{array}$ & $\begin{array}{l}\mathbf{a} \\
\mathbf{b} \\
\mathbf{b}\end{array}$ \\
\hline Thetford (II) & Maurice & IV 5 & 31 & 3 & 60 & + & + & - & + & + & & + & \\
\hline Northampton (III) & $\begin{array}{l}\text { George } \\
\text { Sydney } \\
\text { Alfred } \\
\text { Aubrey } \\
\text { Andrew }\end{array}$ & $\begin{array}{lr}\text { III } & 4 \\
\text { III } & 5 \\
\text { IV } & 3 \\
\text { IV } & 6 \\
\text { IV } & 11\end{array}$ & $\begin{array}{r}38 \\
32 \\
17 \\
13 \\
5\end{array}$ & $\begin{array}{l}2 \\
2 \\
2 \frac{1}{2} \\
3 \\
2 \frac{1}{2}\end{array}$ & $\begin{array}{l}56 \\
59 \cdot 5 \\
54 \cdot 7 \\
53 \\
53\end{array}$ & $\begin{array}{l}+ \\
+ \\
+ \\
+\end{array}$ & $\begin{array}{l}+ \\
+ \\
+ \\
+ \\
+\end{array}$ & $\begin{array}{l}- \\
- \\
- \\
+\end{array}$ & $\begin{array}{l} \pm \\
\pm \\
\pm\end{array}$ & $\begin{array}{l}++ \\
++ \\
++ \\
+ \\
+\end{array}$ & $\begin{array}{c}++ \\
- \\
+ \\
-\end{array}$ & $\begin{array}{l} \pm \\
- \\
- \\
-\end{array}$ & $\begin{array}{l}\text { c } \\
\text { d }\end{array}$ \\
\hline
\end{tabular}

$\mathrm{a}=$ Spasticity of arms.

$\mathrm{b}=$ White speckling on irides.

his hand or lying across his palm. It is uncertain if one or both thumbs were affected.

\section{DISCUSSION}

It must first be admitted that in no case personally examined was there unequivocal evidence of hydrocephalus. As all cases had obviously stabilized it did not seem justifiable to expose them to air studies. While many of the strands in this complex network of evidence relating these many cases are weak the author feels that, taken together, they permit the provisional inference that all these cases conform to a basic pattern, the most important lesion of which is aqueductal stenosis, that this is related to a mutation located on the $\mathrm{X}$ chromosome which is not manifest in the heterozygote, and that various other signs which may or may not be secondary to the main lesion are frequently present. There is great variation in expression within families and an even greater variation between families; these are summarized in Table 1 . In advancing the suggestion that these disturbances are related to a mutation at a specific locus on the $\mathrm{X}$ chromosome, it is not intended to imply that the different mutations at this locus lead to identical functional derangements. The variation in severity between families, $\mathbf{c}=$ Generalized irregular pigmentation.

d = Abnormal restlessness.

which is no greater than that often found in haemophilia, is not inconsistent with mutation from a single gene.

Anatomically the only lesion in the two cases studied in detail (Bickers and Adams, 1949; Edwards et al., 1961) was a stenosis of the aqueduct: in the latter there was also a small pons and an apparent absence of the corticospinal tracts. How this developmental anomaly arises is far from obvious. Defective development of the lumen of a tube can arise either from an excessive growth of its wall, a defective growth of its lining, or an impairment in the forces normally maintaining patency. No abnormal deposits or structures were demonstrated in the wall. Although an early deficiency in cerebrospinal fluid flow can be postulated relevant observations are clearly unattainable. The evidence is consistent with a primary maldevelopment of the lining membrane, although this could be secondary to inadequate functional stimulation. The difficulties of suggesting any mechanism linking a genetic aberration and a stenotic aqueduct are hardly less than those of relating this lesion to the clinical syndrome, which is briefly reviewed in Table 2, and with which it appears to be associated.

The head is large, but even this primary sign is 
unusual in that the enlargement is largely backward and outward, rather than upward, the head being oblong and irregular, and not, as is more usual in hydrocephalus, globular and smooth. Although ventricular dilatation in infancy will obviously explain the abnormality in size, it will not explain the shape, and still less the irregularity and asymmetry.

The face shows a generalized peculiarity, best described as a fleshy coarseness resembling that seen in photographs of professional boxers. This is not adequately explained as a result of apathy as it is more marked than in most mental defectives. The asymmetry can obviously not be explained in functional terms.

The hands pose a curious problem, the thumbs frequently showing a functional abnormality which is not associated with any marked neurological abnormality of the upper limbs, and is not easily dismissed as a non-specific finding in spasticity. The simplest explanation associates it with the unusually large area of cortical representation of the thumb. The abnormalities of the lower limbs, the well-known spastic-spindling which is frequently found in hydrocephalus, is probably of no diagnostic value in differentiation of various types of hydrocephalus, although it may suggest hydrocephalus when the head enlargement is not marked. The occasional co-existence of flexor plantar responses with marked spasticity is possibly more specific.

It is tempting to associate these peculiarities with a primary and highly specific disturbance of cortical control, and to associate this with a primary deficiency of the corticospinal tracts. This deficiency would be interpreted as either secondary to early ventricular dilatation or as an independent consequence of the same genetic shortcoming.

The syndrome as a whole cannot be adequately related to the focal lesion so far described. This hardly reduces the likelihood of the syndrome being a genuine entity as in the majority of morphological disturbances actuated by simple genetic mechanisms it is impossible to unravel the pedigree of causation by which a single metabolic aberration leads to multiple and apparently unrelated structural abnormalities. As an example of similar inadequately explained coexistent associations in a well-defined syndrome with a similar hereditary mechanism we may mention the association of mental deficiency and electrocardiographic abnormalities with Duchenne's type of muscular dystrophy (Dubowitz, 1961).

The inheritance seems clear cut and unequivocally sex-linked in the familial cases presented. Eight presumptively heterozygous women interviewed showed no suggestion of any partial manifestation. One was of very low intelligence, but this could easily be fortuitous; another was very intelligent. The facies, head shape, head size and gait were unremarkable in all. The segregation ratio is grossly abnormal with an excess both of affected males and heterozygous females. This is probably due to informal ascertainment of a rare and previously unrecognized syndrome. It is difficult to allow for this form of bias. If such disturbances in segregation were a consistent feature of mutation at this locus then very large pedigrees might be anticipated, and it would be surprising that these have not already been reported. If the segregation ratio is undisturbed the frequency of the syndrome in males will be three times the mutation rate, and the mutation rate is unlikely to greatly exceed $10^{-5}$. As the incidence of hydrocephalus is approximately $10^{-3}$ this suggests that something of the order of less than $5 \%$ of male hydrocephalics may be due to this disorder. The recurrence rate in hydrocephalus is less than this, three series combined giving a recurrence incidence of one in 200 sibs (see Edwards et al., 1961): it is possible that this syndrome may be the commonest variety of familial hydrocephalus if we exclude hydrocephalus secondary to spina bifida.

The syndrome may present with mental deficiency, the hydrocephalus being minimal with spasticity of the legs being the only definite physical sign. In this form it is probably very rare. Penrose (1938) in his study of 1,280 mental defectives with details of the mental state and physical abnormalities of all sibs, the parents and other affected relatives, found 66 cases of diplegia of prenatal origin. There was a slight excess of males (36 to 30) and a marked excess of consanguineous marriages (six). As only one family (propositi 52 and 53 in the series), with two diplegic male imbeciles, one normal male and two normal females, showed an exclusively male familial segregation, sex-linked diplegia, if it occurred at all in this series, was clearly far rarer than autosomal recessive diplegia.

\section{SUMMARY}

A series of cases of a syndrome consisting of mental deficiency, a slightly enlarged irregular head, spasticity with wasting and contractures limited to the legs and a curious facies is reported. Frequently associated findings include flexion deformity of the thumbs and a parodoxical plantar reflex which is flexor in spite of marked spasticity. It is suggested that this syndrome represents a pattern of signs found in conjunction with a variety 
of aqueductal stenosis related to a mutation on the $\mathrm{X}$ chromosome.

I am most grateful to Dr. Clifford Parsons, Dr. I. H. Gosset, Dr. Christopher Ounsted, Professor L. S. Penrose and Dr. M. J. Peto for their introductions to these families, and to the staff of the Children's Hospital, Birmingham, for permitting me to quote results of investigations and to duplicate photographs.

\section{REFERENCES}

Bamatter, F. (1949). Acquisitions récentes concernant les hydrocéphalies inflammatoires chez l'enfant. Travail d'habilitation de la faculté de Medicine de Genève (dactylographié). 87. (Quoted by Borle.)
Bickers, D. A. and Adams, R. D. (1949). Hereditary stenosis of the aqueduct of Sylvius as a cause of congenital hydrocephalus. Brain, 72, 246.

Borle, A. (1953). Sur l'étiologie de l'hydrocéphalie congénitale. À propos d'un cas d'hydrocéphalie concordante chez des jumeaux univitellins. J. Génét. hum., 2, 157.

Dubowitz, V. (1961). In Report of symposium on muscular dystrophy. Lancet, 1, 275.

Edwards, J. H., Norman, R. M. and Roberts, J. M. (1961). Sexlinked hydrocephalus. Arch. Dis. Childh., 36, 481

Gellman, V. (1959). Congenital hydrocephalus in monovular twins. Ibid., 34, 274.

Penrose, L. S. (1938). A clinical and genetic study of 1,280 cases of mental defect. Spec Rep. Ser med Res Coun. (Lond.), No. 229 mental defect. Spec. Rep. Ser. med. Res. Coun. (Lond.), No. 229. bifida and congenital hydrocephaly. Ann. Eugenics, 13, 73 .

Perez, M. L. and Linger, L. (1947). Hidrocefalia fetal a repeticion. Rev. méd. cubana, 48, 280.

Zimmer, K. (1952). Über familiäres Auftreten von Hydrozephalus. Geburtsh. u. Frauenheilk., 12, 447. 